\title{
A Preferência Visual por Ateliês de Artesanato e Costura
}

\author{
Visual Preference for Craft and Sewing Ateliers
}

\author{
ARAÚJO, Layane Nascimento de \\ Universidade Federal de Pernambuco, Mestranda em Design \\ layane.n.araujo@gmail.com
}

\section{COSTA FILHO, Lourival}

Universidade Federal de Pernambuco, Doutor em Desenvolvimento Urbano

lourivalcosta@yahoo.com

\section{VILLAROUCO, Vilma}

\author{
Universidade Federal de Pernambuco, Doutora em Engenharia de Produção \\ villarouco@hotmail.com
}

\section{RESUMO}

A pesquisa aqui apresentada visou avaliar a qualidade visual em ateliês de artesanato e costura, percebida por artesãos da tipologia fios - rendas, bordados - e costureiras, a fim de indicar os efeitos de certas características ambientais na preferência visual por esses espaços. Para tal, foi adotada uma Sentença Estruturadora, instrumento básico da Teoria das Facetas, para estruturar a investigação empírica, que utilizou o Sistema de Classificações Múltiplas para coletar os dados e a Tabela de Frequência para analisálos. Os resultados empíricos mostraram que o baixo contraste (alta coerência), e alta complexidade eleva a qualidade visual percebida nesses espaços e, por conseguinte, a vontade de trabalhar neles.

ateliê de artesanato e costura, qualidade visual percebida, ergonomia do ambiente construído

\begin{abstract}
The research presented here aimed to analyse the visual quality in craft and sewing studio perceived by thread - lace, embroidery - and seamstress artisans, in order to indicate the effects of certain environmental characteristics on the visual preference for these spaces. To this end, a Mapping Sentence, basic instrument of Facet Theory, was adopted to structure the empirical investigation, which used the Multiple Sorting Procedure to collect data and the Frequency Table to analyse them. The empirical results showed that the high coherence (low contrast) and high complexity increase the perceived visual quality in these spaces and, consequently, the desire of work on them.
\end{abstract}

craft and sewing studio, perceived visual quality, ergonomics of the built environment 


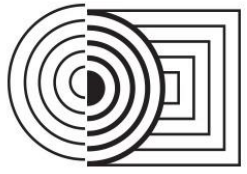

$17^{\circ}$ ERGODESIGN \& USIHC 2019

PUC-Rio, 11 a 13 de dezembro

Rio de Janeiro, RJ, Brasil $17^{\circ}$ Ergodesign - Congresso Internacional de Ergonomia e Usabilidade de Interfaces Humano Tecnológica: Produto, Informações Ambientes Construídos e Transporte

$17^{\circ}$ USIHC - Congresso Internacional de Ergonomia e Usabilidade de Interfaces Humano Computador

\section{INTRODUÇÃO}

Caracterizado por informar aspectos locais e regionais, o artesanato e a costura compreendem tanto valores simbólicos quanto culturais e socioeconômicos. Essas atividades geralmente empregam materiais e recursos da própria localidade, cujos conhecimentos são transmitidos de modo tácito, de geração em geração.

São várias as tipologias artesanais, que variam de matéria-prima e de processo produtivo, desde o barro, madeira, fios, pedra, ferro, couro, fibras e até mesmo o papel. Entre essas tipologias, a escolhida para a pesquisa foi a tipologia fios que, por ser tradicional, abrange atividades manuais, como o bordado e a renda, e industriais como a tecelagem e a costura. Segundo Barros (2008), a renda, no geral, tem origem árabe, e por muito tempo foi associada às épocas das cortes europeias, como produto de luxo. Trazida pela rainha de Portugal D. Maria I, ao Brasil, em 1808, a renda e o bordado inspirados nas primeiras rendas vindas da corte, passaram a ser produzidos no Nordeste brasileiro.

Já a costura corresponde a uma atividade que ocorre desde outrora, não se sabendo ao certo quando surgiu. Entretanto, a primeira máquina de costura panteada da história foi criada por Thomas Saint em 1790, para a costura de calçados. Já para a confecção de vestuário, em 1930, Barthelemy Thommonier criou máquina apropriada.

Apesar de a produção em massa, oriunda da industrialização, com as grandes fábricas de tecelagem na Inglaterra, no século XVIII, as costureiras atualmente ganharam campo devido ao público que busca vestuários e assessórios personalizados e exclusivos, fazendo com que os ateliês de artesanato e costura continuem em evidência.

Apresentada uma rápida contextualização do objeto de estudo empírico da pesquisa, cabe destacar que o ambiente construído tem o potencial de evocar respostas favoráveis ou desfavoráveis aos seus usuários. Assim, sem diminuir o papel de um designer habilidoso, as pesquisas na área da psicologia ambiental e da ergonomia do ambiente construído buscam avançar no conhecimento dessa influência ambiental sobre o afeto, na medida em que essa informação pode ser usada para orientar as decisões de projeto e produzir soluções mais agradáveis aos usuários.

Essa perspectiva de um projeto ergonômico afetivo, segundo Mont'Alvão (2008) ao citar Khalid (2004), é um novo paradigma na área da ergonomia, que tradicionalmente vem se ocupando com questões relacionadas ao usuário - desempenho e estudo de dores e constrangimentos -, pois, como o usuário avalia é mais do que avaliar o usuário.

Nesse sentido, a pesquisa aqui apresentada relaciona-se com a análise empírica de atributos ambientais notáveis em cenas de ateliês de artesanato e costura, sendo de particular relevância o quadro teórico proposto por Stephen Kaplan, delimitado aqui como objeto de estudo teórico. Kaplan (1988) descreve a preferência ambiental em função do "fazer sentido", para que se possa atuar nele, e "envolvimento", para que se possa ser atraído por ele. A coerência, que melhora a compreensão e o valor estético do ambiente, tem a ver com o primeiro propósito, já a complexidade, que produz envolvimento e aprimora o valor estético até certo ponto, está relacionada com o segundo. Pela provável influência dessas duas características sobre a qualidade visual percebida, ambas foram tomadas para estudo nesta pesquisa.

A combinação de alta coerência (baixo contraste) e de média complexidade é destacada nas pesquisas empíricas de avaliação ambiental como preferível, enquanto a associação de baixa coerência (alto contraste) e baixa complexidade representa o oposto (NASAR, 2000). Muitas dessas pesquisas empíricas, entretanto, concentram-se na América do Norte e na Europa Ocidental, justificando a importância de se verificar a consistência desses achados teóricos em um contexto local, como foi realizada e será aqui apresentada. 


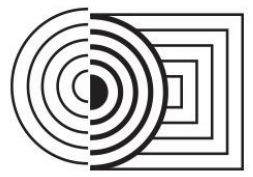

\section{$17^{\circ}$ ERGODESIGN \& USIHC 2019 \\ PUC-Rio, 11 a 13 de dezembro \\ Rio de Janeiro, RJ, Brasil}

$17^{\circ}$ Ergodesign - Congresso Internacional de Ergonomia e Usabilidade

de Interfaces Humano Tecnológica: Produto, Informações Ambientes

Construídos e Transporte

$17^{\circ}$ USIHC - Congresso Internacional de Ergonomia e Usabilidade

de Interfaces Humano Computador

A partir do exposto, buscou-se avaliar a qualidade visual em ateliês de artesanato da tipologia fios - rendas, bordados - e de costura, fundamentada em informações empíricas sobre os efeitos da coerência (avaliada aqui através do contraste entre os elementos na cena) e da complexidade desses espaços, percebidos por participantes que realizam atividades artesanais na modalidade fios: crochê, renda, bordado e/ou costura.

Presumivelmente, a avaliação ambiental influencia o comportamento, de modo que as pessoas têm maior probabilidade de permanecer em um local percebido como favorável e de evitar um outro que seja percebido negativamente. Embora as respostas avaliativas, isoladamente, não possam prever o comportamento real, a avaliação combinada das respostas avaliativas e do comportamento esperado fornece uma boa indicação do comportamento real (NASSAR, 1988). Por essa razão, nesta pesquisa, os participantes foram solicitados a indicar entre diferentes cenas de ateliês de artesanato da tipologia fios - rendas, bordados - e de costura, em qual teriam a vontade de trabalhar (uma expressão da qualidade visual percebida).

Em relação aos procedimentos metodológicos, esta pesquisa de campo, do tipo exploratória, adotou uma Sentença Estruturadora, instrumento básico da Teoria das Facetas, para estruturar a investigação empírica, e selecionou o Sistema de Classificações Múltiplas para coletar os dados, que foram interpretados com base em uma Tabela de Frequência.

Antes de apresentar a Sentença Estruturadora para a avaliação da qualidade visual percebida em ateliês de artesanato e costura, além dos outros procedimentos metodológicos da pesquisa, faz-se necessário apresentar as considerações teóricas que fundamentaram a escolha das duas variáveis de conteúdo que, hipoteticamente, são aderentes para a avaliação pretendida.

\section{CONSIDERAÇÕES TEÓRICAS}

No campo da ergonomia, de acordo com Van Der Linden (2007), uma nova forma de tratar a relação entre humanos e objetos, que inclui temas como estética, prazer e emoção, surgiu a partir do congresso da IEA (International Ergonomics Association) realizado na Finlândia, em 1997, e tem sido denominada de New Human Factors.

Na visão de Mont'Alvão e Damázio (2008), emoção, prazer, afeto, satisfação eram termos, até pouco tempo, praticamente ausentes do vocabulário da Ergonomia e do Design. Hoje, contudo, eles vêm ganhando cada vez mais espaço, dando relevo à ideia de que as pessoas estabelecem relações afetivas com os objetos que as cercam.

Segundo Russell (1988), uma avaliação afetiva ocorre quando uma pessoa julga algo como tendo uma qualidade afetiva, isso é, se esse algo é agradável, amigável, excitante e assim por diante. As avaliações afetivas se assemelham tanto a emoções quanto a cognições. As emoções, por sua vez, equiparam-se aos componentes afetivos, às cognições e à forma de interpretação que o indivíduo faz do entorno.

A avaliação afetiva pode ser usada tanto para avaliar um ambiente, como para comparar ambientes entre si. Sendo assim, Russel $(1988)$ afirma que a qualidade visual de um ambiente é definida por meio da sua qualidade afetiva, ou seja, a capacidade que um ambiente tem de fazer o indivíduo sentir algo. Além disso, o autor ainda afirma que as avaliações afetivas de um ambiente acontecem com base em categorias de preferência visual e que essas também podem ser mensuradas, ou seja, é possível estimar a avaliação afetiva de determinado ambiente, por meio de uma média de um grupo de indivíduo. E "é natural que, a quantidade de concordância entre esses indivíduos seja estabelecida de maneira empírica" (RUSSEL, 1988). Kaplan (1988) advoga que a reação de uma pessoa em relação a um espaço depende do propósito dessa pessoa em relação a esse espaço. Logo, para entender a preferência 


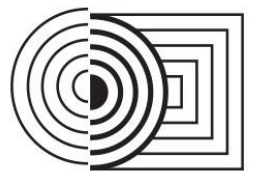

\section{$17^{\circ}$ ERGODESIGN \& USIHC 2019 \\ PUC-Rio, 11 a 13 de dezembro \\ Rio de Janeiro, RJ, Brasil}

$17^{\circ}$ Ergodesign - Congresso Internacional de Ergonomia e Usabilidade

de Interfaces Humano Tecnológica: Produto, Informações Ambientes

Construídos e Transporte

$17^{\circ}$ USIHC - Congresso Internacional de Ergonomia e Usabilidade

de Interfaces Humano Computador

ambiental, deve-se primeiramente entender os propósitos de seus usuários. Pessoas diferentes possuem diferentes propósitos, bem como têm experiências diferentes; e, indivíduos diferentes não podem avaliar o mesmo ambiente da mesma maneira, nem o mesmo indivíduo em épocas diferentes, já que os propósitos podem mudar ao longo do tempo.

Associado a tal discussão, Russel (1988) expõe que a mensuração de avaliações afetivas deve levar em conta sua relatividade. Ainda sobre o tema, Kaplan (1988) afirma que há dois propósitos importantes para a sobrevivência humana em relação ao ambiente: fazer sentido, que se refere à preocupação em entender, compreender as coisas ao seu redor, e envolvimento, relacionado com a preocupação de descobrir, aprender e ser estimulado. Para analisar esses dois propósitos humanos relacionados com a preferência por ambientes, Kaplan (1988) apresenta dois componentes ambientais: a complexidade e a coerência, sendo o primeiro relacionado com o envolvimento, e o segundo com o fazer sentido.

Conforme o autor citado, o primeiro componente, complexidade, reflete o que está havendo numa cena em particular, o quanto há para observar; e se existem poucas coisas, o interesse do observador é baixo. Isso é, a complexidade garante o envolvimento do indivíduo com relação ao ambiente, e, em excesso, pode gerar incerteza e estresse. Não obstante, pouca complexidade pode deixar o ambiente monótono e enfadonho.

Já o segundo componente, coerência, inclui os fatores que fazem o cenário fácil de organizar, de compreender e de estruturar, ou seja, é formulado por coisas que facilitem a organização de padrões e, consequentemente, a compreensão, ou seja, a coerência dá sentido ao ambiente: quanto mais coerente é o espaço, menos incerto pode ser para seu usuário (KAPLAN, 1988). O autor aborda que a variação do contraste é um dos indicadores de preferência usado para auxiliar na coerência do ambiente. Contudo, o excesso de contraste pode trazer insegurança aos observadores, enquanto o baixo contraste pode vir a destacar suas partes essenciais. Kaplan (1988) expõe que é necessário para uma cena ter ao menos um pouco de complexidade e um pouco de coerência para ser preferida. No entanto, como explicado anteriormente, altos valores desses dois componentes não necessariamente estão relacionados com um alto nível de preferência.

Nessa perspectiva, partindo do propósito de que o entorno deve ter média complexidade e baixo contraste (alta coerência) para elevar a qualidade visual percebida, antes de prosseguir com as avaliações da qualidade visual percebida em ateliês de artesanato e costura, faz-se necessária a apresentação das considerações metodológicas que foram utilizadas para a realização da investigação empírica desta pesquisa.

\section{CONSIDERAÇÕES METODOLÓGICAS}

Para a estruturação da investigação empírica foi adotada uma Sentença Estruturadora, instrumento básico da Teoria das Facetas, metateoria criada e desenvolvida por Louis Guttman, escolhida por se configurar como um procedimento metodológico, que vem sendo empregado com sucesso na avaliação de ambientes (COSTA FILHO, 2014) e que "corresponde à classificação de objetos e observações empíricas (variáveis) em categorias exclusivas e abrangentes com relação a um aspecto temático distinto estudado pelo pesquisador" (BILSKY, 2003), podendo assim, ser modelada à situação aqui enfocada: avaliação da qualidade visual percebida em ateliês de artesanato e costura.

Conforme Bilsky (2003), a Teoria das Facetas é um procedimento de pesquisa que abarca três aspectos diferentes. Primeiro, apresenta fundamentos sobre como projetar pesquisas para a coleta sistemática dos dados; e, por se tratar de procedimento metateórico, oferece um marco 


\section{$17^{\circ}$ ERGODESIGN \& USIHC 2019 \\ PUC-Rio, 11 a 13 de dezembro \\ Rio de Janeiro, RJ, Brasil}

$17^{\circ}$ Ergodesign - Congresso Internacional de Ergonomia e Usabilidade de Interfaces Humano Tecnológica: Produto, Informações Ambientes Construídos e Transporte

$17^{\circ}$ USIHC - Congresso Internacional de Ergonomia e Usabilidade de Interfaces Humano Computador

de referência formal que facilita o desenvolvimento de teorias. Segundo, pode ser considerada como adequada para a análise de variáveis psicológicas e sociais, já que apresenta uma variedade de métodos que se destacam por um mínimo de restrições estatísticas. Terceiro, estabelece uma relação sistemática com o estudo, o registro e análise dos dados coletados, facilitando expressar suposições teóricas por meio de hipóteses, de modo que seja possível validá-la empiricamente.

Ainda segundo o mesmo autor, a Teoria das Facetas opera com três tipos de facetas: o primeiro tipo se refere à população de indivíduos que avaliarão as variáveis (facetas). 0 segundo tipo se refere ao conteúdo dessas variáveis (as facetas de população e de conteúdo, juntas, definem o domínio da pesquisa). E o terceiro tipo, que corresponde às possibilidades de respostas, ou seja, um racional que é comum a todas as facetas.

Nesta pesquisa, a primeira faceta está relacionada com artesãos da tipologia fios - rendas, bordados - e costureiras; o segundo tipo de faceta, com base no que foi levantado no referencial teórico, reúne duas características ambientais presentes em ateliês de artesanato e costura - contraste e complexidade - como variáveis de conteúdo; e a terceira apresenta a variedade de cinco respostas possíveis: (1) nada; (2) pouco; (3) mais ou menos; (4) muito; (5) demais. Tais características foram estabelecidas na sentença estruturadora para a avaliação da qualidade visual percebida em ateliês de artesanato e costura. Todas essas categorias, segundo Bilsky (2003), transmitem - de maneira sucinta - todo o delineamento das facetas que definem uma determinada pesquisa.

O Quadro 1 apresenta a sentença estruturadora para a avaliação da qualidade visual percebida em ateliês de artesanato e costura. Como é possível notar, as duas características tomadas como facetas de conteúdo, contraste e complexidade, variando em três diferentes níveis, foram organizadas de forma semelhante a uma análise combinatória, e geram nove diferentes situações (A3xB3=9AB) a serem avaliadas ou pesquisadas. Cada uma dessas situações específicas compartilha de um racional, que apresenta a variedade de cinco respostas possíveis: (1) nada; (2) pouco; (3) mais ou menos; (4) muito; (5) demais, e os números entre parênteses representam os valores a serem tabulados no momento da análise dos dados. A Sentença Estruturadora, como uma hipótese inicial da pesquisa, será analisada em relação aos resultados empíricos que devem confirmar ou contestar essa estrutura. Dessa forma, após a interpretação dos dados e na fase final, há informações suficientes para construir ou não uma nova Sentença Estruturadora como consequência direta dos resultados empíricos encontrados (COSTA FILHO, 2014).

Quadro 1 - Sentença para a avaliação da qualidade visual percebida em ateliês de artesanato e costura

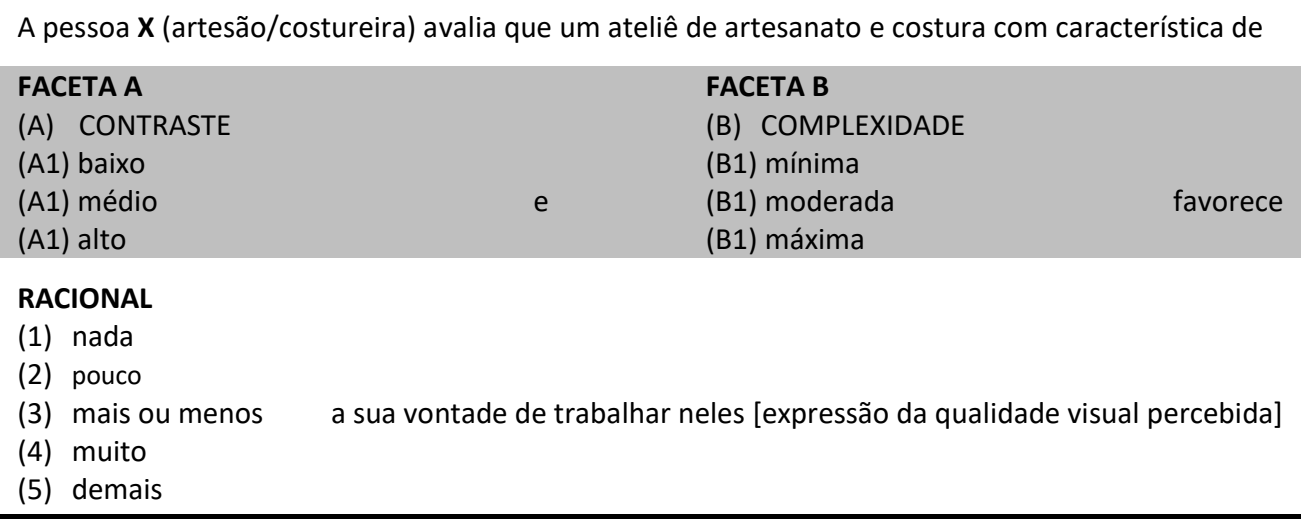




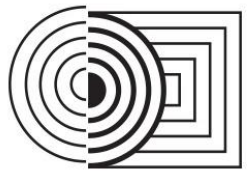

\section{$17^{\circ}$ ERGODESIGN \& USIHC 2019}

PUC-Rio, 11 a 13 de dezembro

Rio de Janeiro, RJ, Brasil $17^{\circ}$ Ergodesign - Congresso Internacional de Ergonomia e Usabilidade de Interfaces Humano Tecnológica: Produto, Informações Ambientes Construídos e Transporte

$17^{\circ}$ USIHC - Congresso Internacional de Ergonomia e Usabilidade de Interfaces Humano Computador

O conjunto das nove cenas escolhidas, com $13 \mathrm{~cm}$ de altura, utilizadas como elementos de estímulo para as classificações dirigidas, está diretamente relacionado às variáveis da pesquisa, listadas na Sentença Estruturadora para a avaliação da qualidade visual percebida em ateliês de artesanato e costura, e todas foram selecionadas no site Pinterest (Figura 1).

Figura 1. Ateliês de artesanato/costura representando as relações de contraste e complexidade consideradas

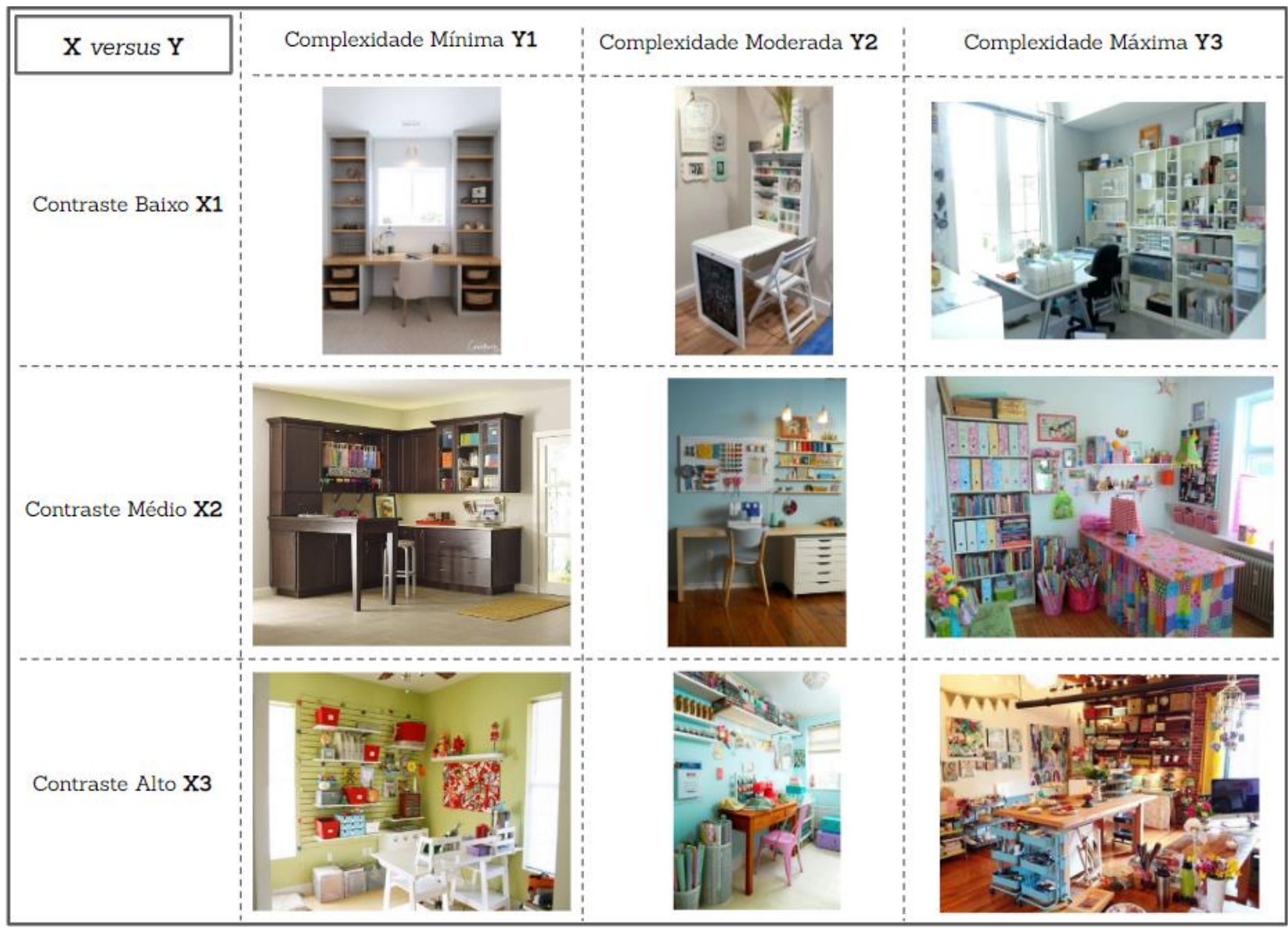

Fonte: Pinterest (2018)

Como ferramenta para coleta de dados, foi utilizado o Sistema de Classificações Múltiplas que, para Costa Filho (2014), consiste em solicitar ao participante da pesquisa que separe ou agrupe os elementos de estímulo, diversas vezes, de acordo com sua similaridade, em função de critérios de livre escolha ou estabelecidos pelo pesquisador. Dessa forma, esse procedimento pode gerar várias classificações com base no número de categorias que o usuário desejar dividir ou agrupar.

Costa Filho (2014) aponta várias vantagens no uso do Sistema de Classificações Múltiplas: mecanismo simples e de frequente utilização quanto a sua qualidade de coleta de dados, possibilidade de se utilizar imagens e, ainda, pelo fato de exigir pouco dos entrevistados. Com relação aos procedimentos adotados na abordagem dos participantes, inicialmente foi informado que: o estudo focava na avaliação de ateliês de artesanato e costura; não havia resposta certa ou errada; garantia-se sigilo e anonimato. Em seguida, era pedido que o participante - após se identificar por sexo, idade, nível de escolaridade - indicasse em que 


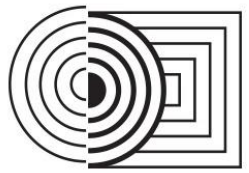

\section{$17^{\circ}$ ERGODESIGN \& USIHC 2019 \\ PUC-Rio, 11 a 13 de dezembro \\ Rio de Janeiro, RJ, Brasil}

$17^{\circ}$ Ergodesign - Congresso Internacional de Ergonomia e Usabilidade de Interfaces Humano Tecnológica: Produto, Informações Ambientes Construídos e Transporte

$17^{\circ}$ USIHC - Congresso Internacional de Ergonomia e Usabilidade

de Interfaces Humano Computador

medida as cenas desse tipo de espaço favorecia a sua vontade de trabalhar neles.

Com base no Sistema de Classificações Múltiplas, cada entrevistado recebia as nove cenas de ateliês de artesanato e costura, todas fotografias de ambientes reais e coloridas, e as avaliações ocorreram com base no critério exposto, ou seja, preestabelecido pelo pesquisador. Cabe destacar que esta pesquisa foi desenvolvida para uma Disciplina ofertada no Programa de Pós-Graduação em Design da UFPE, onde a primeira autora está regularmente matriculada, e as nove cenas apresentadas nas classificações dirigidas foram selecionadas com a ajuda do grupo de alunos e o professor, que atuaram como juízes sobre os níveis de contraste e de complexidade relacionados com cada uma delas.

Para a intepretação dos dados, contou-se com uma Tabela de Frequência (MARCONI; LAKATOS, 2017), que descreve as repetições agrupadas dos valores obtidos nas classificações dirigidas, permitindo melhor compreensão dos fenômenos.

\section{CONSIDERAÇÕES DE RESULTADOS}

Como critério de inclusão, foi considerado que os participantes realizassem atividades manuais na modalidade fios: crochê, renda, bordado e/ou costura. Após o término, esta pesquisa abordou doze pessoas: todas mulheres, com idade entre 28 e 74 anos, e nível de escolaridade Superior Completo (8), além de Ensino Médio Fundamental Completo (4).

O Quadro 2 lista as avaliações atribuídas para cada uma das nove cenas de ateliês de artesanato e/ou costura por cada respondente. A primeira linha relaciona as nove cenas de ateliês de artesanato e/ou costura, indo de contraste baixo (coerência alta) e complexidade baixa, cena X1Y1, até contraste alto (coerência baixa) e complexidade alta, cena X3Y3. A primeira coluna do Quadro 2 lista as doze respondentes desta pesquisa, e, ao realizar o cruzamento das linhas e colunas, obtêm-se as avaliações atribuídas por cada entrevistado para cada uma das nove cenas de ateliês de artesanato e/ou costura com diferentes qualidades visuais. Ao final, na última linha, têm-se os escores obtidos para cada uma das cenas, com o intuito de se apurar qual delas era a preferida e qual delas representava o oposto.

Quadro 2 - Tabela de Frequência das avaliações atribuídas para as 9 cenas por cada artesão

\begin{tabular}{|c|c|c|c|c|c|c|c|c|c|}
\hline ATELIÊS & X1Y1 & $\mathrm{X} 1 \mathrm{Y} 2$ & X1Y3 & X2Y1 & X2Y2 & X2Y3 & X3Y1 & X3Y2 & X3Y3 \\
\hline PESSOA & & & & & & & & & \\
\hline 01 & 4 & 3 & 5 & 3 & 3 & 1 & 3 & 3 & 2 \\
\hline 02 & 1 & 2 & 2 & 3 & 4 & 5 & 4 & 2 & 2 \\
\hline 03 & 4 & 2 & 5 & 3 & 2 & 3 & 2 & 2 & 5 \\
\hline 04 & 4 & 3 & 5 & 4 & 3 & 5 & 4 & 4 & 5 \\
\hline 05 & 3 & 2 & 4 & 4 & 3 & 3 & 4 & 4 & 5 \\
\hline 06 & 2 & 3 & 4 & 4 & 5 & 3 & 4 & 5 & 3 \\
\hline 07 & 4 & 3 & 4 & 2 & 3 & 2 & 3 & 3 & 1 \\
\hline 08 & 2 & 2 & 3 & 3 & 4 & 4 & 3 & 3 & 3 \\
\hline 09 & 5 & 2 & 5 & 3 & 2 & 4 & 3 & 2 & 5 \\
\hline 10 & 3 & 2 & 4 & 3 & 2 & 3 & 4 & 4 & 5 \\
\hline 11 & 3 & 3 & 5 & 4 & 2 & 4 & 4 & 5 & 5 \\
\hline 12 & 2 & 2 & 3 & 3 & 5 & 3 & 4 & 5 & 2 \\
\hline TOTAL & 37 & 29 & 49 & 39 & 38 & 40 & 42 & 42 & 42 \\
\hline
\end{tabular}

Fonte: autores da pesquisa com base nos dados coletados (2019)

Desse modo, com base na Tabela de Frequência apresentada acima, tem-se que a cena do ateliê de artesanato e/ou costura em que os artesãos respondentes sentiram mais vontade de 


\section{$17^{\circ}$ ERGODESIGN \& USIHC 2019}

PUC-Rio, 11 a 13 de dezembro

Rio de Janeiro, RJ, Brasil $17^{\circ}$ Ergodesign - Congresso Internacional de Ergonomia e Usabilidade de Interfaces Humano Tecnológica: Produto, Informações Ambientes Construídos e Transporte

$17^{\circ}$ USIHC - Congresso Internacional de Ergonomia e Usabilidade de Interfaces Humano Computador

trabalhar foi a X1Y3, que apresenta contraste baixo (coerência alta) e complexidade alta (Figura 2), enquanto a cena X1Y2, que apresenta contraste baixo (alta coerência) e complexidade moderada (Figura 3), representa o oposto.

Avaliando as escolhas acima nota-se que o contraste baixo (coerência alta) eleva a qualidade visual percebida na cena, o que favorece a fácil leitura e atuação no espaço, segundo as participantes. Para Kaplan e Kaplan (1982), com base em Kaplan (1988), a legibilidade é característica de um ambiente possível de se explorar extensivamente, sem se perder nele, ou seja, quanto mais baixo o nível de contraste mais coerente, clara e legível se torna a compreensão do ambiente pelo usuário.

Logo, para o tipo de atividade considerada, artesanato e costura, o contraste baixo é preferível, pois o contraste alto pode provocar fadiga visual e cansaço. Desse modo, para a realização de uma atividade em que a visão é essencial, faz-se necessário um ambiente com tal característica. Em contrapartida, combinado com complexidade alta, já que, embora a complexidade em excesso gere incerteza e pode estressar o indivíduo, o aumento na quantidade de elementos em cena aumenta o número de estímulos e deixa o ambiente mais envolvente, e combinado ao contraste baixo (coerência alta), como é o caso da cena X1Y3, acaba por equilibrar essa equação, deixando o ambiente mais atrativo, segundo os participantes desta pesquisa.

Figura 2 - Cena MAIS preferida

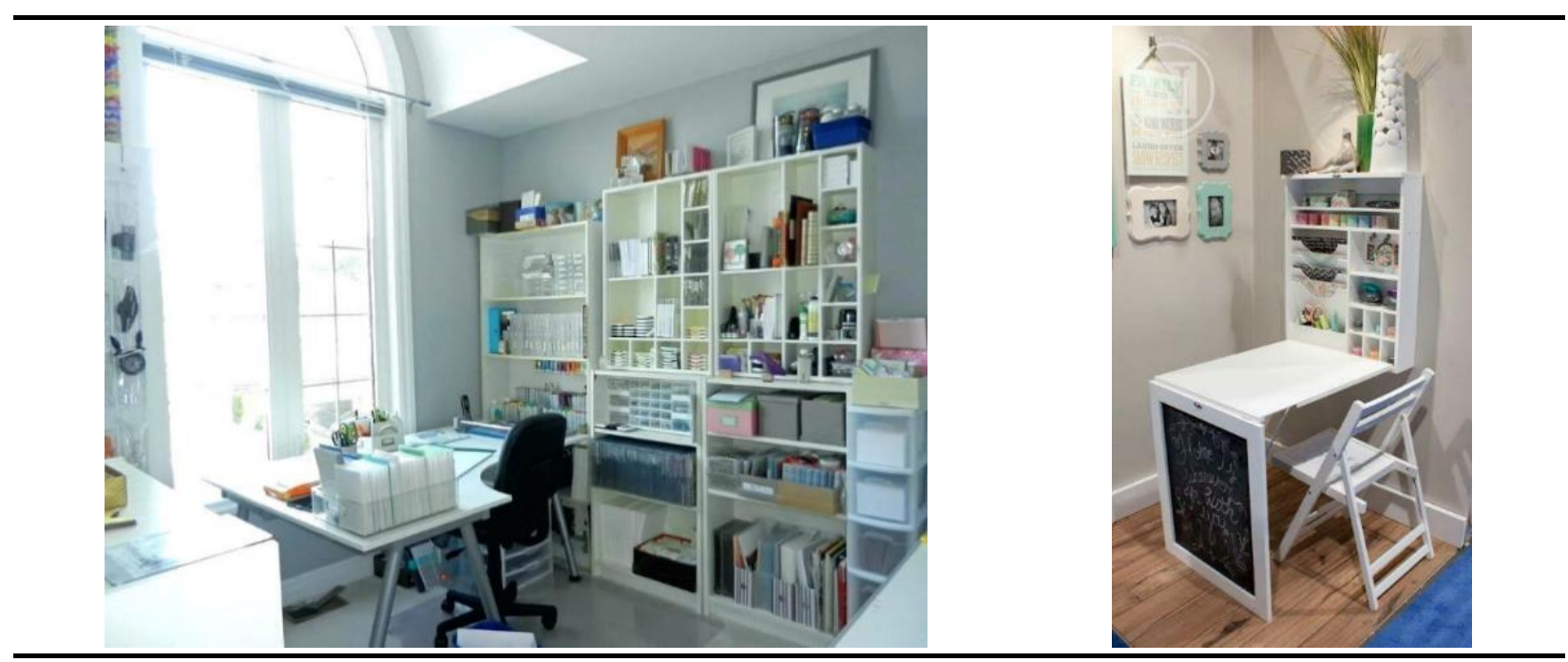

Fonte: Pinterest (2018)
Figura 3 - Cena MENOS preferida

Fonte: Pinterest (2018)

O baixo contraste foi dado por tons pastéis, cores análogas e efeitos menos estimulantes, transmitindo tranquilidade para o trabalho em um ateliê de artesanato e/ou costura. Entretanto, o ambiente não corre o risco de se tornar enfadonho/monótono, podendo até provocar acidentes de trabalho, uma vez que há um elevado número de elementos na cena e, consequentemente, de estímulo produzido pela complexidade alta (muitos elementos na cena). Já a cena preterida, X1Y2, tem complexidade moderada e número moderado de elementos, tal qual o ambiente preferido, o que acaba deixando o espaço menos estimulante para a atividade. Outro critério preditor da preferência, embora desconsiderado nesta pesquisa, pode ter exercido influência nas avaliações realizadas, haja vista que todas as imagens com os mais altos escores têm aberturas, que ampliam visualmente os espaços, podendo ter contribuído com a preferência pela cena $\mathrm{X} 1 \mathrm{Y} 3$, por exemplo, que apresenta duas aberturas e muitos locais para 


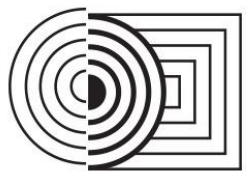

\section{$17^{\circ}$ ERGODESIGN \& USIHC 2019 \\ PUC-Rio, 11 a 13 de dezembro \\ Rio de Janeiro, RJ, Brasil}

$17^{\circ}$ Ergodesign - Congresso Internacional de Ergonomia e Usabilidade de Interfaces Humano Tecnológica: Produto, Informações Ambientes Construídos e Transporte

$17^{\circ}$ USIHC - Congresso Internacional de Ergonomia e Usabilidade

de Interfaces Humano Computador

acomodar os apetrechos de trabalho. Inversamente, a cena preterida, X1Y2, sem nenhuma abertura, aparenta confinamento e tem poucos locais para armazenar o material necessário.

\section{CONCLUSÃO}

Após apuração dos resultados empíricos, verificou-se que a Sentença Estruturadora para a avaliação da qualidade visual percebida em ateliês de artesanato e costura, bem como o instrumento de coleta de dados, Sistema de Classificações Múltiplas, atenderam de modo satisfatório aos propósitos considerados.

Buscando avaliar a qualidade visual percebida em ateliês de artesanato e costura, apurou-se, através das classificações dirigidas, realizadas com artesãs/costureiras, que o contraste baixo (coerência alta) associado à complexidade máxima elevam tal condição, enquanto o contraste baixo (coerência alta) combinado à complexidade moderada representa o oposto.

Esse achado corrobora apenas parcialmente com a tese de Kaplan (1988) para a preferência humana por ambientes com contraste baixo (coerência alta) e complexidade moderada, tomadas como hipóteses iniciais desta pesquisa.

Apurou-se, ainda, embora de forma indireta, que as cenas com aberturas e mais espaços para acomodar os apetrechos de trabalho foram muito valorizadas e podem ter ajudado a elevar a qualidade visual percebida nas cenas de ateliês de artesanato e costura, embora essa suspeita precise ser investigada em futuras investigações, em um outro momento, para corroborar ou contestar essa nova faceta, ficando aqui como recomendação para trabalhos futuros.

A partir de tais resultados, espera-se que as informações empíricas aqui apresentadas possam contribuir para aprimorar a metodologia do projeto ergonômico para esse tipo de espaço de trabalho e, por conseguinte, para a sua qualidade visual percebida.

\section{REFERÊNCIAS BIBLIOGRÁFICAS}

BARROS, M. C. R. O artesanato alagoano: Filé. In: IV COLÓQUIO DE MODA, Novo Hamburgo, 2008. Anais: Novo Hamburgo, 2008. Disponível em: http://coloquiomoda.hospedagemdesites. ws/anais/anais/4-Coloquio-de-Moda_2008/42268. Acesso em maio 2018.

BILSKY, W. A Teoria das Facetas: noções básicas. In Estudos de Psicologia, v.8, n.3, 2003. p. 357-365.

COSTA FILHO, L. L. O enfoque da teoria das facetas na avaliação de lugares. In: V ENEAC ENCONTRO NACIONAL DE ERGONOMIA DO AMBIENTE CONSTRUÍDO E VI SEMINÁRIO NACIONAL DE ACESSIBILIDADE INTEGRAL, 2014. Rio de Janeiro. Anais... Rio de Janeiro, PUC-Rio, LEUI/PUC - Rio. 2014..

KAPLAN, S. Perception and landscape: conceptions and misconceptions. In NASAR, J. (Ed.). Environmental aesthetics: theory, research, and application. New York: Cambridge University Press, 1988. p. 45-55.

MARCONI, M.; LAKATOS, E. Técnicas de pesquisa: planejamento e execução de pesquisas, amostragens e técnicas de pesquisas, elaboração, análise e interpretação de dados. 8. Ed. São Paulo: Atlas, 2017.

MONT'ALVÃO, C.; DAMAZIO, V. Apresentação. In: MONT'ALVÃO, C.; DAMAZIO, V. (Orgs.). Design, Ergonomia, Emoção. Rio de Janeiro: MAUDE Editora Ltda e FAPERJ, 2008.

MONT'ALVÃO, C. Hedonomia, Ergonomia Afetiva: afinal, do que estamos falando? In: MONT'ALVÃO, C.; DAMAZIO, V. (Org.). Design, Ergonomia, Emoção. Rio de Janeiro: MAUDE Editora Ltda e FAPERJ, 2008. 
NASAR, J. L. The evaluative image of places. In WALSH, W. B.; CRAIK, K. H; PRINCE, R. H. 2nd ed. (Eds.). Person-environment psychology: new directions and perspectives, pp 117-168. New Jersey: Lawrence Erlbaum Associates, 2000.

. The effect of sign complexity and coherence on the perceived quality of retail scenes. In NASAR, J. L. (Ed.). Environmental Aesthetics: theory, research, \& applications. New York: Cambridge University Press, 1988. p. 300-320.

RUSSEL, J. Affective appraisals of environments. In NASAR, J. (Ed.). Environmental aesthetics: theory, research, and application. New York: Cambridge University Press, 1988. p. 120-129.

VAN DER LINDEN, J. Ergonomia e Design: prazer, conforto e risco no uso dos produtos. Porto Alegre: UniRitter Ed., 2007. 